\title{
Third: A Screenplay on the Importance of Acceptance in an Attempt to Move on from Grief
}

\author{
Gunawan, V. \\ English for Creative Industry, Faculty of Letters, Petra Christian University, Siwalankerto 121-131, Surabaya \\ 60236, East Java, INDONESIA \\ Email: vince.n.tioes@gmail.com
}

\begin{abstract}
Although everyone must have gone through a stage of grief in their life, often times people are not aware of how to properly deal with it and are having difficulties to move on. There is a misconception in the society that mourning is a negative emotion that one should get over with as soon as possible. Using the Tasks of Grief theory, however, I discovered that this misconception of the grieving process tends to lead someone into denial, as they are not urged to accept the emotions carried out by the grief. To illustrate how denial can hinder someone from finding closure to their grief, I created a fifteen-minute screenplay which tells the story of a man who seems to have moved on from his breakup with an ex-lover while, in fact, he is living in a denial by his attempt to mask his own emotions. After a series of event, the protagonist gradually comes to accept the true nature of his loss and finally moves on with his life. I hope that this creative work will influence the audience and society to remove the misconception of suppressing emotions and forgetting the deceased being a way out of their grief.
\end{abstract}

Keywords: Grief, Moving On, Denial, Acceptance, Tasks of Grief, Mourning, Closure

\section{INTRODUCTION}

In accordance with my double-degree program in the Film and Video Department as well as my passion in film, I decided to choose narrative short screenplay as the form of my final project. Throughout my two years' study in the Film and Video Department of Dongseo University, I have become quite used to writing short films with duration between 8 to 15 minutes. I felt that writing screenplays with this duration was a good step to prepare myself for a feature-length one in the future. I did not want to try writing a feature-length screenplay yet because I was quite aware of my limited skills and experience as well as resources such as time and funding that a feature film would require. By writing a screenplay in this length, I felt that the chance of having this screenplay made into film would be bigger than if it were a feature-length one; and seeing their screenplay turned into a complete movie is surely the goal of every screenwriter.

The screenplay I wrote would fall into drama genre, with a hint of romance. The reason why I chose to work with drama genre is because I feel that it is one of the most ideal genres to be made into short films especially for an independent production with relatively low budget. This genre also offers a relatively wider range of topics to work with, making it easier to connect with a broader group of target audience (Filmsite, n.d.-a). In addition, since the beginning I wanted to work with a theme that the audience could relate to differently for each individual; which could be more easily achieved through drama than other genres.

Two topics that are generally found in drama films are love and sadness; simply because everyone is familiar with both of these emotions as they are often tied together. Out of the two, however, I was more interested to explore the topic of sadness; to be more specific, with the topic of grief that accompanies the death of loved ones. Without a doubt, anyone must have gone through a moment of grief at some point of their life. Even to a child, the concept of death has been introduced early on by parents to explain the absence of certain family members or relatives. As the child grows up, they will witness the passing of their grandparent and experience grief themselves; frankly this experience grows more often as the individual got older. While the concept of grief is no longer new to them, the process of grieving often becomes more complex as they experience various levels of closeness to the deceased 
(Maine Center for Disease Control and Prevention [MCFDCAP], n.d.). When the grieving is caused by the death of a partner or someone they hold very close, it is not rare for the bereaved to be stuck in their grief and unable to "move on" due to their attachments to the deceased. While most of the time these people are easily distinguishable, there can be cases where the bereaved try to mask their feelings and pretend to be okay when they are actually not; trapping themselves in their own denial.

Based on that topic, I had an idea to write a short film in which the main character was trapped in a similar situation. It is basically a story about In-seok, a man in his early thirties, who had been living only half a life ever since the unexpected death of his lover, Young-eun, despite his denial about it. He buried himself in work and avoided unnecessary social interactions to help him move on from her; the memories kept coming back at him in daydreams nevertheless. When he was reminded of his promise to attend what would have been their third anniversary dinner, In-seok was faced with two choices: ignore it and keep on living like that forever or fulfill this promise, for whatever its worth, and risk getting hurt even more.

The purpose of this creative work is to show that withdrawal from social interactions and denial are often indicators of one's inability to move on from their grief. I also want to show that finding a sort of closure towards their grief is necessary for someone to move on with their life. To be more specific, through this project, I want to show that In-seok's withdrawal from social interactions, delusion of Young-eun coming to their anniversary and denial of his inability to move on show that he has not overcome his grief, and that In-seok needs to accept the death of Young-eun and let his attachments of her go in order to move on with his life.

As the big theme of my screenplay is moving on from grief, I decided to explore the Theories of Grief and Loss, a series of theories which covers the study of mourning and bereavement among individuals, in order to understand more on how grief affects individuals psychologically. Among the several branches of this theory, I decided to use the Tasks of Grief theory developed by William J. Worden because it is the one that focuses in the importance of acceptance for a successful moving on.

In his book Grief Counseling and Grief Therapy: A Handbook for the Mental Health Practitioner (2009), William J. Worden defines grieving as consisting of four tasks that the bereaved need to accomplish - not necessarily in the following order - to successfully complete their mourning. The first task is to accept the reality of the loss, which are often more difficult when the death is sudden. In this case, there is a tendency for the bereaved to be stuck in denial of the reality of the death. The denial can be obvious, such as talking about the deceased as if they were alive, or subtler, like by pretending that their relationship to the deceased was of no significance. Worden states that, "another way that people protect themselves from reality is to deny the meaning of the loss. In this way, the loss can be seen as less significant than it actually is" (2009, p. 40).

The second task is to work through the pain of grief, which often comes in the form of sadness, anger, hurt, emptiness, and loneliness that accompany the loss of loved ones. Other negative emotions, like regret for unfinished business in the case of sudden death, or guilt and blame in suicide, as well as fear and anxiety if the death was caused by a homicide can also be carried by the pain of grief. Whatever emotions the bereaved is experiencing, it is important that they do not ignore and try to diminish them or "it can manifest itself through physical symptoms or some form of aberrant behavior" (2009, p. 44). Instead, the bereaved need to acknowledge these emotions and discuss about them in order to gain an understanding and put them in perspective.

The third task is to adjust to an environment in which the deceased is missing. This task required the bereaved to identify and fill the roles which were occupied by the deceased through a process of rearranging, restructuring and redefining of these roles. Fulfilling this task can be much more difficult when the deceased played a major role in the bereaved individual's life. It is also important to note that the roles left by the deceased are not limited to concrete physical roles but may also encompass emotional roles as well. As a matter of fact, these emotional roles - like finding someone to make us smile - are often more difficult to cope with. For this readjustment to take place, the bereaved must first recognize all of the implications that the death has brought to their life and come to terms with these gaps. 
The fourth and final task is to emotionally relocate the deceased and move on with life. Emotional relocation of the deceased means shifting the focus from the feelings of loss and longing that accompany the awareness that the deceased is really gone from the bereaved individual's life forever to being able to keep that person as a memory and as a part of their life. The bereaved does not necessarily forget about the deceased; rather they "need to find ways to memorialize, that is, to find ways to remember dead loved ones-keeping them with us but still going on with life" (2009, p. 50), be it in a new relationship or in something that commemorates the life of the deceased. Only when this task is completed can the bereaved truly complete their grieving process and move on with life.

In my screenplay, In-seok is portrayed as someone who has not moved on through the incompletion of the first three tasks. Regarding the first task, he might have acknowledged the death of Young-eun as a fact, but the way he tries to undermine the significance of his relationship with her indicates that he has not completely accepted the reality of his loss and is living in denial. For the second task, instead of working through the pain of his grief, In-seok tries to repress all of the negative emotions brought by the death and hide them beneath his working routines. As a result, these feelings are never truly gone; they resurface as feelings of emptiness and numbness every time he is reminded of her death and eventually manifests into his hallucination of her coming back to him. As for the third task, In-seok fails to adjust to this new environment in which Young-eun was absent by failing to identify and refill the emotional role that she played in his life. He rejects the idea of Young-eun being the one person who could make him smile and loosen up nor tries to find a substitute to fill that role. Instead, he believes he can function perfectly well even with the lack of this emotional role.

As the story progresses, however, the incompletion of these tasks gradually comes to his realization. When he receives a confirmation call for what would have been their third anniversary dinner, In-seok's hesitation on whether or not he should come indicates the significance of this relationship to him. Logically, there should be no reason for him to attend the dinner since he is very much aware of Young-eun's death. Instead, he decided to come because he was burdened by his promise to her to be there no matter what, which means she must have meant a lot to him and that his tough act was a form of denial. As he imagined Young-eun joining him for the dinner later, In-seok is reminded of the feeling of comfort and happiness that he used to feel. However, only when the waiter breaks him out of his hallucination does In-seok truly realized how Young-eun's absence has also taken away those feelings out of his life, which can yet be replaced. This realization comes to him so hard that In-seok can no longer suppress his true feelings. Though involuntarily, In-seok is finally able to work his way through the pain of grief by letting go of an emotional burst at the end of the scene. When all three tasks are finally completed, In-seok steps out of his denial and comes to full awareness of the loss that Youngeun's death has brought him. This does not make him move on, however, since he is still overwhelmed by all of the negative emotions carried by the loss. With the help of Young-eun's appearance, In-seok realizes the need to let go of his longing for her and let her live on as a memory instead, thus finally moving on from his grief.

\section{OUTLINE OF THE CREATIVE WORK}

\subsection{Theme}

The subject matter that I choose to work with is moving on and the theme that I want to talk about through this screenplay is how denial can hinder someone from moving on from their grief. First and foremost, I feel that it is necessary to understand what the term moving on really means. Over the past couple of years, the term "move on" has grown popular, especially among youths, even in nonEnglish speaking countries such as Indonesia. The usage of this term has been very closely associated with a failed romantic relationship, in which someone would be labeled as "already moved on" or "not moved on yet" according to whether or not they have gotten over their ex-lover. Meanwhile, the literal definition of moving on is "any kind of action or decision to stop thinking or worrying or remembering about an event or a task". With these two meanings combined, people have come to believe that moving on in this sense carries the concept of forgetting the source of the grief and being no longer (emotionally) affected by the loss. 
However, this is actually a misconception that has led many people to be trapped in denial of their loss. In order to move on, they force themselves to forget about the person they lost and repress any negative emotions caused by the loss, which will be exceptionally hard in the case of sudden loss and death. As a result, their social life will be negatively affected as they would be hesitant in starting new relationship in order to stay "safe". In some cases, this denial might even cause delusions or other psychological disorder when their repressed emotions go out of hand. With this screenplay, I want the audience to see how living in denial will only negatively affect one's life and hinder them from truly moving on.

\section{2. Pitch}

a. After his partner, Young-eun, suddenly left him, In-seok buries himself in work as a distraction from the memory.

b. As he is reminded of a promise to attend what would have been their third anniversary dinner, Inseok is torn between keeping that promise or avoiding from getting hurt even more.

c. In the end, In-seok can finally accepts Young-eun's death and let go of his attachment after her appearance in his hallucination.

\subsection{Synopsis}

In-seok is a journalist in his early thirties who is working for a travel magazine in Busan, South Korea. He is quite a loner who prefers to work alone and stay in his comfort zone. Having been assigned to work with Young-eun - an intern photographer around the same age as his - for a few times, he eventually fell in love with her, despite their seemingly opposing personality. They started dating and the relationship lasted for nearly three years, until Young-eun suddenly left In-seok by himself just three months before their third anniversary. Ever since, In-seok buried himself in work and limited himself from social interactions in an attempt to get over the bitter memory of his past relationship. He pretended to be living normally without Young-eun, but his denial caused him to daydream about his good times with her.

On the day of their third anniversary, he is reminded of a promise he had made to attend their upcoming anniversary dinner. Trapped in his delusion that there was still a chance for them to get back together, In-seok decided to keep his promise and come. After a while, Young-eun showed up and despite the initial awkwardness - they quickly caught-up with each other and In-seok seemed to regain his happiness. When they got interrupted by a waiter there, however, In-seok realized that he was only imagining Young-eun's presence all along.

The following day, In-seok went to a cemetery garden and set down a bouquet of flowers in front of a tombstone with Young-eun's name on it. He was about to burst into tears when he felt Young-eun hugged him from behind and told him to let her go. In-seok turned to find no one there but managed to force a smile on his face.

\section{4. Step Outline}

1. Black out. The landscape of a mountain in Summer from afar, seen as if through a DSLR camera's viewfinder.

2. A young woman, Young-eun, appears in front of the camera, holding a stem of wild flower.

3. The man holding the camera, In-seok, scold Young-eun for playing around while they are working.

4. Young-eun told him not to be so serious all the time and drags him down to the grass.

5. Both lying on the grass, Young-eun tells In-seok how she envies birds for being able to travel anywhere so freely.

6. In-seok disagree, saying that he prefers to have a place he can call home.

7. In-seok and Young-eun end up holding hands.

8. A different voice wakes In-seok from his dream. 
9. In-seok is sitting in his desk in some sort of an office that is quite empty. On his computer/laptop screen is a picture like the one he saw in his dream earlier.

10. He turns and finds his colleague telling him to go home.

11. In-seok makes an excuse and urges his colleague to go ahead.

12. His colleague tells him to check his phone since it has been vibrating for a while.

13. In-seok does so and finds several missed calls from an unknown number and a reminder saying "3rd anniversary".

14. As he is about to delete the event reminder, he receives a call from the same number. It is a confirmation call for a reservation under the name Young-eun at a restaurant for that night.

15. In-seok takes a look at a somewhat dusty desk calendar nearby which reads "August". He checks the date on his computer/laptop, flip over a few pages until it reaches "November" and sees a post-it attached on the 10th saying “3rd Anniversary: Tavern @7 pm. Don’t be late!!".

16. The voice on the phone asks again if they should keep the reservation or not, but In-seok just stares at his reflection in the window.

17. In-seok is walking back and forth in front of a fancy restaurant. He is dressed very nicely and is holding a bouquet of flowers.

18. As he is about to leave, the restaurant manager approaches him and shows him to a table for two by the window.

19. A waiter shows him the menu but he tells him to give him more time.

20. He looks out to the beach/sea through the window for a while. He has a flashback of himself giving a surprise to Young-eun, the woman from his dream, at the beach.

21. Then she tells him that next time she will be the one giving the surprise and made him promise to come no matter what happens.

22. Young-eun's voice brings her back to the present.

23. In-seok turns away from the window and is stunned to see Young-eun sitting across him.

24. She starts apologizing for making him wait for her and everything, but In-seok just seems delighted to see her despite everything.

25. They order food and start chatting and laughing.

26. In the end, Young-eun says that she is surprised and glad that In-seok decides to come despite what has happened.

27. A waiter comes and asks him if he is still waiting for someone. In-seok turns his head and realizes that no one is sitting across him.

28. The following day, In-seok is walking through the small forest/meadow which appeared in his flashback. He is holding the bouquet from the previous day, which is already slightly wilted.

29. He stops at a cliff area which is secured by police/safety lines and puts down the flower.

30. For a moment he just stands/kneels there, staring blankly. Then his eyes start to stream with tears.

31. As his sob grows more intense, a woman hugs him from behind and whispers something to his ear.

32. In-seok turns but finds no one there. Slowly, he manages to put up a little smile and walks away.

33. The camera shows the site, where there is a framed picture of Young-eun on the ground and the flower bouquet in front of it.

\section{5. Characters}

- Park In-seok

Age : early 30s

Gender : Male

Park In-seok was a senior journalist for a travel magazine where Kim Young-eun was doing an internship. He had always been rather quiet and seemingly cold because he tended to keep things to himself. His personality began to change as he grew closer to Young-eun, who had an opposing personality. They had been dating for almost three years when Young-eun left him all 
of a sudden. Since then, In-seok withdrew himself from any social life and tried to bury himself with work. Instead of helping him to move on with life, In-seok unconsciously got more and more attached to his memories that it was getting hard distinguishing between his daydreams and reality.

- Kim Young-eun

Age : late 20s/early 30s

Gender : Female

Kim Young-eun started off as a part-time photographer at the publishing company In-seok worked in where they met and eventually date each other after working together for a couple of times. Unlike In-seok, Young-eun is a free-willed, free-spirited girl who had been wandering from place to place and always seeking for new adventures. She did not really want to settle down in one place for a long time and be attached in a serious relationship, but somehow she got interested with In-seok and decided to change her mind. Until nearing the end of the film, Youngeun was told to have left In-seok all of a sudden after almost three years of dating each other, but the reason was not told to the audience.

- The colleague

Age : early to mid 30s

Gender : Male

In-seok's co-worker at the publishing company. He was not necessarily In-seok's closest friend, but was one of the few who still persistently tried to get In-seok out of his solitude ever since Young-eun left him a couple months back. He had been working in the company long enough to know about In-seok and Young-eun's relationship and how she left him in the end.

- Waiter/waitress

The waiter/waitress appeared in the $2^{\text {nd }}$ scene only through a voice call to confirm with In-seok about a reservation at a restaurant, and later in the $3^{\text {rd }}$ and $5^{\text {th }}$ scene when In-seok came to the restaurant.

\section{CONCLUSION}

Based on the research I did for the construction and development of this screenplay, I have found several points that serve as answers to the questions that I have stated earlier on in this paper. First of all, I have found that there are a number of indicators, among which are denial and withdrawal from social interactions, that can be used to identify individuals who are having difficulties to move on from their grief. In my screenplay, In-seok's inability to overcome his grief is indicated by his attempt to suppress his feelings of loss and to undermine the significance of his relationship with Young-eun and by burying himself in work in order to avoid anything that might remind him of her. I have also found that completing the four tasks of grief, especially the fourth task which is to emotionally relocate the deceased, is crucial for a bereaved individual in order to find a closure to his grief and move on with their life. This is shown, in my screenplay, by In-seok's change of attitude as he finally steps out of his denial and realizes that Young-eun would want him to move forward with his life.

Working on this project made me realize that despite being one of the most popular genres, writing a drama screenplay is not as easy as it seems. As the focus of a drama film is on the emotional and relational developments between the characters, I was required to do thorough research on human's psychology and observation on real-life day to day interactions among people with similar background to my characters in order to make them realistic and convincing. It was especially challenging when the character's personality was quite an opposite to my own personality, which made me have to constantly remind myself to be that character - to act and say dialogues that might be unfamiliar to me - whenever I was writing about him. Also, as my screenplay is for a short film, I have to accustom myself to limit the dialogues and do the storytelling through the visual aspects instead. 
This means even as a writer I must not shy away from including specific actions or behaviors, settings, and even camera angles in details if it is necessary for the storytelling.

By working on this topic, I have learned that in order to successfully overcome grief, one should embrace the truth of the loss and live on with it. To accept the truth means not only being aware that one has lost someone but also letting them feel the emotions that the loss brings them. Sometimes people tend to act tough and guarded because they think that blocking the emotions is the way adults deal with grief, while in fact this will only hinder them from moving on with their lives. Thus, letting oneself drown in the emotions of grief is completely acceptable since only then those emotions are no longer burdening their life and eventually can be invested in future relationships.

\section{REFERENCES}

Buffam, N. (n.d.). Genre: Drama. Retrieved March 17, 2017, from http://thescriptlab.com/screenplay/genre/drama

Dirks, T. (n.d.-a). Drama films. Retrieved June 01, 2017, from http://www.filmsite.org/dramafilms.html

Dirks, T. (n.d.-b). Romance films. Retrieved June 01, 2017, from http://www.filmsite.org/romancefilms.html

Maine Center for Disease Control and Prevention. (n.d.). Tasks of grief [PDF]. Retrieved March 17, 2017, from https://www1.maine.gov/suicide/docs/Survivor-Kit/Tasks-Grief.pdf

Worden, J. W. (2009). Grief counseling and grief therapy: A handbook for the mental health practitioner (Fourth ed.). New York: Springer Publishing Co.

Gorer, G. (1965). Death, grief, and mourning. London: Cresset Press.

Webb, M. (Director), \& Novick, M., Tuchinsky, J., Waters, M., \& Wolfe, S. J. (Producers). (2009). 500 days of summer [Motion picture on DVD]. United States: Fox Searchlight Pictures.

Aronofsky, D. (Director), \& Franklin, S., Handel, A., Medavoy, M., Messer, A., \& Oliver, B. (Producers). (2010). Black swan [Motion picture on DVD]. United States: Fox Searchlight Pictures.

Gondry, M. (Director), \& Golin, S., \& Bregman, A. (Producers). (2004). Eternal sunshine of the spotless mind [Motion picture on DVD]. United States: Focus Features.

Fincher, D. (Director), \& Linson, A., Caffin, C., \& Bell, R. G. (Producers). (1999). Fight club [Motion picture on DVD]. United States, Germany: 20th Century Fox.

Scorsese, M. (Director), \& Medavoy, M., Messer, A. W., Fischer, B. J., \& Scorsese, M. (Producers). (2010). Shutter island [Motion picture on DVD]. United States: Paramount Pictures.

Lee, Y. (Director), \& Shim, J., \& Lee, E. (Producers). (2012). 건축학개론 (Architecture 101) [Motion picture on DVD]. South Korea: Lotte Entertainment.

Norman-Golding, C. (1970, January 01). Codes and conventions of the drama genre and how they fit into my imagined film. Retrieved March 15, 2017, from http://chantellefm1.blogspot.co.id/2013/04/codes-and-conventions-of-drama-genre.html 